\title{
Cloud radiative effect, cloud fraction and cloud type at two stations in Switzerland using hemispherical sky cameras
}

\author{
Christine Aebi $^{1,2}$, Julian Gröbner ${ }^{1}$, Niklaus Kämpfer ${ }^{2}$, and Laurent Vuilleumier ${ }^{3}$ \\ ${ }^{1}$ Physikalisch-Meteorologisches Observatorium Davos, World Radiation Center, Davos, Switzerland \\ ${ }^{2}$ Oeschger Center for Climate Change Research and Institute of Applied Physics, University of Bern, Bern, Switzerland \\ ${ }^{3}$ Federal Office of Meteorology and Climatology MeteoSwiss, Payerne, Switzerland \\ Correspondence to: Christine Aebi (christine.aebi@pmodwrc.ch)
}

Received: 9 June 2017 - Discussion started: 25 July 2017

Revised: 9 October 2017 - Accepted: 9 October 2017 - Published: 30 November 2017

\begin{abstract}
The current study analyses the cloud radiative effect during the daytime depending on cloud fraction and cloud type at two stations in Switzerland over a time period of 3 to 5 years. Information on fractional cloud coverage and cloud type is retrieved from images taken by visible all-sky cameras. Cloud-base height $(\mathrm{CBH})$ data are retrieved from a ceilometer and integrated water vapour (IWV) data from GPS measurements. The longwave cloud radiative effect (LCE) for low-level clouds and a cloud coverage of 8 oktas has a median value between 59 and $72 \mathrm{Wm}^{-2}$. For midand high-level clouds the LCE is significantly lower. It is shown that the fractional cloud coverage, the $\mathrm{CBH}$ and IWV all have an influence on the magnitude of the LCE. These observed dependences have also been modelled with the radiative transfer model MODTRAN5. The relative values of the shortwave cloud radiative effect $\left(\mathrm{SCE}_{\mathrm{rel}}\right)$ for low-level clouds and a cloud coverage of 8 oktas are between -90 and $-62 \%$. Also here the higher the cloud is, the less negative the $\mathrm{SCE}_{\text {rel }}$ values are. In cases in which the measured direct radiation value is below the threshold of $120 \mathrm{Wm}^{-2}$ (occulted sun) the $\mathrm{SCE}_{\text {rel }}$ decreases substantially, while cases in which the measured direct radiation value is larger than $120 \mathrm{Wm}^{-2}$ (visible sun) lead to a $\mathrm{SCE}_{\text {rel }}$ of around $0 \%$. In 14 and $10 \%$ of the cases in Davos and Payerne respectively a cloud enhancement has been observed with a maximum in the cloud class cirrocumulus-altocumulus at both stations. The calculated median total cloud radiative effect (TCE) values are negative for almost all cloud classes and cloud coverages.
\end{abstract}

\section{Introduction}

The influence of clouds on the radiation budget and radiative transfer of energy in the atmosphere are the greatest sources of uncertainty in simulations of climate change (Boucher et al., 2013). Small changes in cloudiness and radiation can have large impacts on the Earth's climate. There are two competing influences of clouds on the surface radiation budget (Sohn and Bennartz, 2008). On one hand, clouds reflect incoming shortwave radiation and thus diminish the incoming energy at the Earth's surface. On the other hand, they prevent longwave radiation from the surface and lower atmosphere from escaping the atmosphere. Radiation is the energy source which modifies the atmospheric thermodynamic structure, the Earth's general circulation and the climate system (Sohn and Bennartz, 2008). The effect of clouds is not only of importance in the long-term temporal and spatial averages but also on shorter timescales (seconds to minutes). Furthermore, the exchange of energy due to the formation of clouds and precipitation is an important component of the global water cycle and in turn of climate change (Trenberth, 2011). Thus, the influence of clouds has to be measured and analysed in more detail.

Not only the cloud amount but also other cloud parameters such as cloud type and cloud optical thickness are of importance. The physical parameters defining the various cloud types may have distinct effects on radiation of different wavelengths. For example, optically thin and high-level clouds have a relatively small effect on the downward shortwave radiation, whereas low-level and thick clouds scatter and absorb a large part of the solar radiation and re-emit it as thermal radiation in all directions. Thus, cloud-type variations 
can alter both shortwave and longwave radiation fluxes due to changes in cloud levels, water content and cloud temperatures (Chen et al., 2000; Allan, 2011). However, not only different cloud types but also clouds of the same type may have a distinct influence on the surface radiation budget due to their macrophysical (cloud coverage and geometry) and microphysical properties (e.g. optical thickness and particle size distribution; Pfister et al., 2003). The distribution, frequency and length of occurrence of different cloud types, and the cloud amount in general, may cause a change in climate variations and climate feedback (Bony et al., 2006; Norris et al., 2016). In order to assess the cloud climate feedback, cloud independent parameters such as the time of year or time of day are also of importance (Allan, 2011). Knowledge of the cloud type also allows conclusions to be drawn regarding the current atmospheric motions (Chen et al., 2000). Thus, additional information on the cloud type is crucial for categorising the cloud radiative effect (Futyan et al., 2005).

In detailed numerical weather and climate prediction models, cloud properties (cloud-base height, cloud cover and cloud thickness) and the physical processes responsible for the formation and dissipation of clouds are often approximations and parameterisations (e.g. Bony et al., 2006; Allan et al., 2007; Zelinka et al., 2014; Sherwood et al., 2015). In order to contribute to the accuracy of the representation of clouds in atmospheric prediction models, there is a need for satellite and ground-based in situ measurements (Sohn, 1999; Jensen et al., 2008; Su et al., 2010; Roesch et al., 2011). Satellite measurements have the advantage of covering a wider area. Mainly over the oceans, it is almost the only data source with which information on cloud coverage and cloud type can be obtained (Ohring et al., 2005). However, the temporal resolution of satellite products is limited. From the Meteosat Second Generation (MSG) geostationary satellites, for instance, data on clouds are taken with a time resolution of $15 \mathrm{~min}$ (Werkmeister et al., 2015). Therefore, and for the validation of cloud products from satellites, ground-based observing systems such as all-sky cameras are necessary.

For several years, all-sky cloud cameras have been in use worldwide in order to collect continuous information on clouds from the surface. Many studies already determined cloud coverage based on all-sky camera images (e.g. Long et al., 2006; Kazantzidis et al., 2012; Alonso et al., 2014). Heinle et al. (2010) presented a method for using all-sky camera images to classify cloud types. Wacker et al. (2015) applied this algorithm, with slight modifications, to determine six cloud classes automatically with a mean success rate of 50 to $70 \%$. The current study uses the cloud-type detection and the cloud fraction algorithm presented in Wacker et al. (2015).

The current study presents a study of cloud radiative effect at the surface depending on cloud fraction and cloud types at two stations in Switzerland over a time period of 3-5 years. The data and methods (including the description of the algorithms and the models) are described in Sect. 2. The cloud radiative effect in the longwave and shortwave ranges at the two stations, Davos and Payerne, and sensitivity analyses are presented and discussed in Sect. 3. Conclusions are outlined in Sect. 4.

\section{Data and methods}

\subsection{Data}

Data are available from two stations in Switzerland. The stations are located at two altitude levels. Payerne is located in the Central Plateau ( $46.49^{\circ} \mathrm{N}, 6.56^{\circ} \mathrm{E}, 490 \mathrm{~m}$ a.s.l.) and Davos is located in the Swiss Alps $\left(46.81^{\circ} \mathrm{N}, 9.84^{\circ} \mathrm{E}\right.$, $1594 \mathrm{~m}$ a.s.l.). At both of these stations a visible all-sky camera has been installed. The camera type in Payerne is a VIS-J1006, manufactured by Schreder GmbH (www. schreder-cms.com). This camera system consists of a commercial digital camera (Canon Power Shot A60) with a fisheye lens and a glass dome on top to protect the camera from rain and dust. This camera is sensitive in the red-green-blue (RGB) region of the spectrum and takes two images every 5 min with a resolution of $1200 \times 1600$ pixels each. The two images, taken one just after the other, have different exposure times $(1 / 500$ and $1 / 1600 \mathrm{~s})$ but the same fixed aperture of $f / 8$.

The camera system in Davos is a Q24M from Mobotix (www.mobotix.com). It is a commercial surveillance camera with a fisheye lens that is sensitive in the RGB as well. The resolution of the images is the same as that for the camera in Payerne. In Davos, one image is taken every minute with an exposure time of $1 / 500 \mathrm{~s}$. The Mobotix camera is ventilated and installed on a solar tracker with a shading disk.

The radiation data are retrieved from Kipp and Zonen CMP22 pyranometers (shortwave; 0.3-3 $\mu \mathrm{m}$ ) and from Kipp and Zonen CG4 pyrgeometers (longwave; $3-100 \mu \mathrm{m}$ ) at both stations. All the instruments are cleaned daily and traceable to the respective standard groups of the World Radiation Center (WRC). The temperature data used in the current study are measured at $2 \mathrm{~m}$ height at both stations. The integrated water vapour (IWV) data are based on GPS measurements (Bevis et al., 1992; Hagemann et al., 2003) and retrieved from the STARTWAVE (STudies in Atmospheric Radiative Transfer and Water Vapour Effects) database (Morland et al., 2006). Aerosol optical depth (AOD) data, used for the shortwave cloud-free model, are retrieved from precision filter radiometers (PFR; Wehrli et al., 2000). Ceilometer data for the retrieval of the cloud-base height (CBH) are only available in Payerne. At this station a CHM15k ceilometer from Jenoptik (now Lufft Mess- und Regeltechnik GmbH) is installed (Wiegner and Geiß, 2012).

For the Davos station, the cloud radiative effect (CRE) has been calculated from 7 August 2013 to 30 April 2017 with a time resolution of $1 \mathrm{~min}$. Data have only been taken into account for daytime measurements when the sun is located at a 
minimum five degrees above the horizon and the mountains. For Payerne, the study of CRE includes data from 1 January 2013 to 30 April 2017 with a time resolution of 5 min. Data considered are during the daytime with a solar zenith angle (SZA) of maximum $78^{\circ}$. Cloud camera data availability in these periods is around 98 and $86 \%$ for Davos and Payerne respectively, which mainly results from occasional data gaps of 1 to 3 consecutive days. The lower data availability in Payerne can be explained by two longer time periods of more than 20 consecutive days (one in winter and one in summer) when no camera data are available.

\subsection{Cloud radiative effect}

In the current study, the cloud radiative effect (CRE) is defined as a radiation measurement value minus a modelled cloud-free value. The total cloud radiative effect (TCE) is divided into the shortwave cloud radiative effect (SCE) and longwave cloud radiative effect (LCE)

$$
\begin{aligned}
\mathrm{TCE} & =\mathrm{SCE}+\mathrm{LCE}=\mathrm{DSR}_{\mathrm{obs}}-\mathrm{DSR}_{\mathrm{cfm}} \\
& +\mathrm{DLR}_{\mathrm{obs}}-\mathrm{DLR}_{\mathrm{cfm}}
\end{aligned}
$$

which are both calculated by comparing an observed downward radiation measurement (shortwave $(\mathrm{SW})$ : $\mathrm{DSR}_{\mathrm{obs}}$, longwave (LW): DLR ${ }_{\text {obs }}$ ) with a modelled cloud-free downward radiation value (SW: $\mathrm{DSR}_{\mathrm{cfm}}$ and $\mathrm{LW:} \mathrm{DLR}_{\mathrm{cfm}}$ ). For our calculations, only measurements from downward radiation during the daytime are taken into account. The atmospheric conditions (namely temperature and IWV) in the models are assumed to be the same under cloudy and cloudfree conditions. In the following, the SCE values are given as relative values $\left(\mathrm{SCE}_{\text {rel }}\right)$ and calculated using Eq. (2).

$$
\mathrm{SCE}_{\mathrm{rel}}=\mathrm{SCE} / \mathrm{DSR}_{\mathrm{cfm}} \times 100 \%,
$$

where $\mathrm{DSR}_{\mathrm{cfm}}$ is the modelled cloud-free irradiance value for the corresponding date and time. $\mathrm{SCE}_{\text {rel }}$ is used due to the fact that different solar zenith angles lead to large differences in the absolute SCE values. Clouds increase the measured LW radiation at the surface as they emit LW radiation. Shortwave radiation measured at the surface is usually reduced by clouds as they reflect SW radiation back to space.

\subsection{Cloud-free models}

For the calculation of the cloud radiative effects two cloudfree models, one for the shortwave and the other one for the longwave range, are needed. The cloud-free model for the longwave is an empirical model with input of measured surface temperature and IWV values and a climatology of the atmospheric temperature profile (Wacker et al., 2014). Comparing the LW radiation measurements of the cloud-free cases, detected in the aforementioned time period, with the LW radiation values of the cloud-free model gives a mean difference of $-0.9 \pm 3.9$ and $-0.5 \pm 8.1 \mathrm{Wm}^{-2}$ for Davos and Payerne respectively. Thus, this difference lies within measurement uncertainty as has been shown by Wacker et al. (2014). The shortwave cloud-free model (used in Eq. 2) is a look-up table (LUT) based on radiative transfer model calculations using LibRadtran (Mayer and Kylling, 2005). The input of the model is a standard atmosphere including several measured atmospheric parameters: solar zenith angle (SZA), aerosol conditions (Angstrom coefficient and aerosol optical depth (AOD), both interpolated over 1 day) and IWV. The air mass is calculated with the formula presented by Kasten and Young (1989). The LUT is different for the two stations, Davos and Payerne, considering a different range of values that might occur. Measured values of IWV, SZA and aerosol content are then interpolated with the LUT and downward shortwave cloud-free irradiance values are available for all the single time steps and the corresponding atmospheric conditions. The difference between SW measurement and the cloud-free model depends on the SZA. The bigger the SZA, the higher the mean difference. In Davos, the mean difference changes from $7.2 \pm 20.7 \mathrm{Wm}^{-2}(0.9 \pm 2.6 \%)$ for data with SZA $<50^{\circ}$ to $5.7 \pm 14.7 \mathrm{Wm}^{-2}(1.1 \pm 3.8 \%)$ for data with $\mathrm{SZA}>50^{\circ}$. In Payerne, the mean difference is $7.3 \pm 41.7 \mathrm{Wm}^{-2}(1.0 \pm 5.2 \%)$ for data with $\mathrm{SZA}<50^{\circ}$. The mean difference is with $3.3 \pm 34.1 \mathrm{Wm}^{-2}(0.6 \pm 8.9 \%)$ slightly larger for data with SZA from 50 to $78^{\circ}$.

\subsection{Cloud fraction and cloud-type retrievals}

The calculation of the fractional cloud coverage is based on the all-sky cloud camera images from the aforementioned systems. Before calculating the cloud amount the images must be preprocessed. The distortion of the images is removed with a polynomial function. Additionally a horizon mask must be defined, since Davos is located between two mountain ridges. For both stations the horizon mask has been defined on the basis of an individual cloud-free image. After the preprocessing of the images a colour ratio (the sum of the blue to green ratio plus the blue to red ratio) is calculated per pixel (Wacker et al., 2015). This calculated colour ratio is compared with a reference ratio value which is defined empirically in order to define the cloud classification per pixel. The reference value for Davos is 2.2 and the one for Payerne is 2.5. These values are different due to the differences in camera systems and settings. After comparing the calculated ratio with the reference value a decision can be made per pixel to classify it as cloudy or cloud-free. The fractional cloud coverage is then calculated as the sum of all cloudy pixels divided by the total number of sky pixels. For historical reasons the fractional cloud coverage is given in oktas (CIMO, 2014). In the current study the classification of oktas is taken from Wacker et al. (2015). Thus, zero okta cloud coverage or cloud-free conditions are defined as $0-5 \%$ fractional cloud coverage. Thus, cloud-free does not necessarily mean no clouds at all. On the other end of the scale, 8 oktas is defined as a fractional cloud coverage of $95 \%$ and above, 
which implies that it is not necessarily a fully covered sky. Okta 1-7 are defined in between with steps of $12.75 \%$ fractional cloud coverage. For $65-85 \%$ of the cases (in comparison to different cloud fraction retrieval instruments), the success rate of the fractional cloud cover calculation is \pm 1 okta (Wacker et al., 2015).

The algorithm of Heinle et al. (2010) allows the classification of clouds based on statistical features retrieved from the all-sky cloud images. This algorithm has been slightly adapted by Wacker et al. (2015) and is the one used for the current analysis. The classification is done by first calculating 12 spectral, textural and radiative features. The features under consideration are the mean of the red and the mean of the blue channel, standard deviation and the skewness both of the blue channel, and the differences between the red and green, red and blue, and green and blue channels. The textural features are the energy, contrast and homogeneity of the blue channel and the total cloud coverage. The radiative feature LCE has been added by Wacker et al. (2015) after testing its (positive) influence on the mean success rate of the cloud-type recognition. The classifier used is the k-nearestneighbour (knn) method, which is a supervised method. The training set used to apply the knn method has been determined with visual analysis of the images. The training set is only available for the Payerne station. Thus, for both stations, Davos and Payerne, the same training set has been used. The training set only contains images with one cloud type present. However, the training images display a wide variety of the shapes and positions of the clouds but not necessarily of cloud fractions. In the classification procedure, different cloud types per image might be detected; however as a result, only the one with the most hits is chosen. Thus, only one cloud type per image is determined, although several might be present. The seven classes studied are cloud-free (Cf), cirrus-cirrostratus ( $\mathrm{Ci}-\mathrm{Cs})$, cirrocumulus-altocumulus $(\mathrm{Cc}-$ $\mathrm{Ac}$ ), stratocumulus (Sc), stratus-altostratus (St-As), cumulus $(\mathrm{Cu})$ and cumulonimbus-nimbostratus $(\mathrm{Cb}-\mathrm{Ns})$. In the following, low-level clouds consist of $\mathrm{Cu}, \mathrm{Sc}, \mathrm{St}-\mathrm{As}$ and $\mathrm{Cb}-\mathrm{Ns}$. The cloud class $\mathrm{Cc}-\mathrm{Ac}$ is a mid-level cloud class and $\mathrm{Ci}-\mathrm{Cs}$ is a high-level cloud class. According to Wacker et al. (2015), for a random data set from Davos, the situation Cf was correctly classified in more than $85 \%$ of cases followed by $\mathrm{Ci}-\mathrm{Cs}(65 \%)$ and $\mathrm{Cu}$ (more than $50 \%$ of the cases). For Payerne, around $80 \%$ of the manually classified Sc clouds are also classified as such with the automatic algorithm and a random data set. The second most correctly detected cloud classes are $\mathrm{Cf}$ (more than $70 \%$ of the cases) and $\mathrm{Cb}-\mathrm{Ns}$ ( $68 \%$ of the cases). On average, the success rates are 57 and $55 \%$ for Davos and Payerne respectively (Wacker et al., 2015).

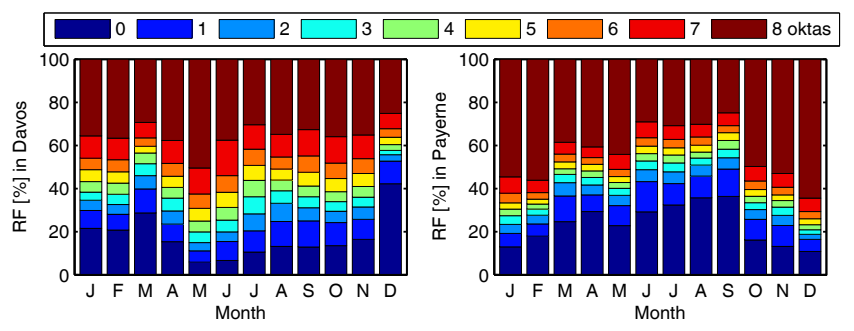

Figure 1. Relative frequencies (RF) of cloud coverages in 1- to 8okta divisions (all cloud types together) for the two stations Davos (left) and Payerne (right).

\section{Results and discussion}

\subsection{Occurrence of cloud fraction and cloud types}

The data sets for the calculation of the CRE consist of 595806 and 117763 images for Davos and Payerne respectively. In Davos, the cloud coverage is 8 oktas for $35 \%$ of the data set. In $17 \%$ of the cases the cloud coverage is zero okta, which is a maximum fractional cloud coverage of $5 \%$. Seven-okta cloud coverage occurs in $11 \%$ of the cases followed by one okta $(10 \%)$. Two to six oktas are all equally distributed in 5 to $6 \%$ of the cases. Also in Payerne, a cloud coverage of 8 oktas is determined in most of the cases $(41 \%)$, followed by zero okta in $25 \%$ of the cases. In $10 \%$ of the cases a cloud coverage of 1 okta is determined followed by 7 oktas (6\% of the cases) and two oktas $(5 \%)$. A cloud coverage of three to six oktas is determined in 3-4\% of the cases. The distribution of the cloud coverage over the months is shown for Davos and Payerne separately in Fig. 1. The colours indicate okta cloud coverages.

In the winter half of the year (with a maximum in March and December) the sky is more often cloud-free than in the summer half of the year in Davos. In contrast, in May the sky is covered with 8 oktas in almost half of the cases. Cloud coverages of 1 to 7 oktas are quite equally distributed over the months. In Payerne the situation is the opposite for cloudfree days with more frequent 8-okta cloud coverage in wintertime, whereas cloud-free situations are more common during summertime. Also in Payerne, cloud coverages of 1 to 7 oktas are fairly equally distributed.

The difference in cloud-free and overcast situations can be explained by the location and the topography of the two stations. In the Central Plateau, where Payerne is located, in the autumn and winter months a common meteorological condition is an inversion, which leads to fog and thus to an overcast sky. Whereas in Davos, located in the Alps, the weather is rather dominated by thermal lift, which occurs more often in summer than in winter.

Regarding the distribution of the cloud coverages in oktas throughout the day, no real pattern can be observed in Davos. In Payerne there are more cloud-free conditions in the early 


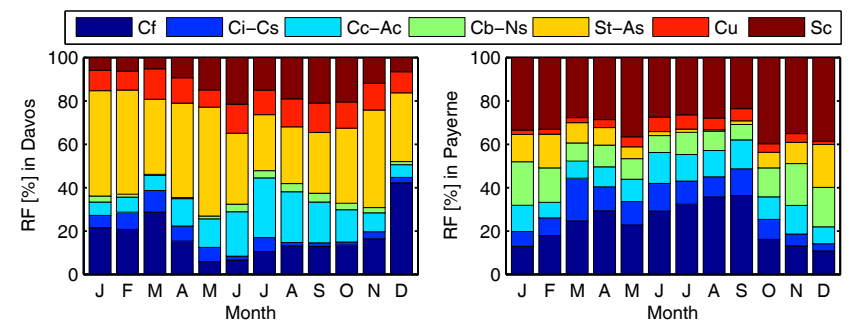

Figure 2. Relative frequencies (RF) of all cloud classes per month (all cloud coverages together) for the two stations Davos (left) and Payerne (right). Cf: cloud-free; $\mathrm{Ci}-\mathrm{Cs}$ : cirrus-cirrostratus; $\mathrm{Cc}-\mathrm{Ac}$ : cirrocumulus-altocumulus; $\mathrm{Cb}-\mathrm{Ns}$ : cumulonimbus-nimbostratus; St-As: stratus-altostratus; $\mathrm{Cu}$ : cumulus; $\mathrm{Sc}$ : stratocumulus.

morning than later in the day. The other okta cloud coverages are also equally distributed throughout the day.

In the 595806 cases from Davos, St-As is the cloud type that is most detected in the studied time period, with $37 \%$ of the analysed cases. The second and third most detected sky conditions in Davos are $\mathrm{Cf}$ and $\mathrm{Cc}-\mathrm{Ac}$ with $17 \%$ and $14 \%$ respectively, followed by Sc (13\%), Cu (12\%), Ci-Cs (5\%) and $\mathrm{Cb}-\mathrm{Ns}(2 \%)$. In the 117763 sky images from Payerne, the cloud type $\mathrm{Sc}$ is detected in $31 \%$ of the cases. This is followed by $\mathrm{Cf}$ in around $25 \%$ of cases, $\mathrm{Cb}-\mathrm{Ns}, \mathrm{Cc}-\mathrm{Ac}$ and $\mathrm{Ci}-\mathrm{Cs}$ (each $11 \%$ ), St-As (7\%) and $\mathrm{Cu}(4 \%)$.

Figure 2 shows the relative frequencies of the cloud classes per month for the two stations Davos and Payerne separately and all cloud coverages together.

In Davos, as determined by our algorithm, from October to May St-As is present in at least $30 \%$ of the cases per month. This fraction of St-As is rather too high and might be due to a limitation of the cloud-type algorithm. The limitation is that the algorithm applied to Davos is trained with images from Payerne. Therefore, it might be more difficult to distinguish between low-level cloud classes (e.g. St-As and Sc) in Davos. This limitation might also be responsible for the rather infrequent determination of $\mathrm{Cu}$ in Davos. The cloud class $\mathrm{Cc}-\mathrm{Ac}$ is more often present in summertime than in wintertime. $\mathrm{Ci}-\mathrm{Cs}$ is almost absent in the months August to October. This absence of the cloud class $\mathrm{Ci}-\mathrm{Cs}$ in the late summer months does not match with the visual analysis of images and might be explained by the fact that the cloud detection algorithm is not sensitive enough to detect thin highlevel clouds. The largest fraction of cloud type in Payerne is Sc for all months. The cloud classes $\mathrm{Cb}-\mathrm{Ns}$ and $\mathrm{St}-\mathrm{As}$ are both more often observed during wintertime than during summertime. The larger frequency of these two cloud types agree with the fact that there is more often fully covered sky in wintertime than summertime.

Regarding the distribution of the cloud classes throughout the day, there are no large differences in the occurrence of cloud types per time of day. The distribution is quite flat for both stations.
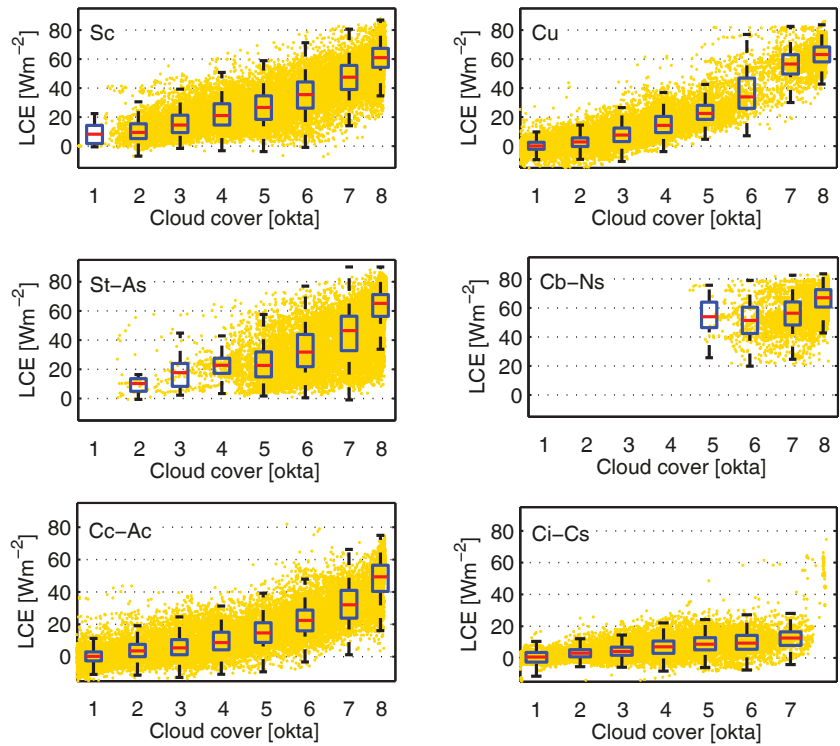

Figure 3. Dependence of the LCE on cloud coverage for Davos for cloud classes stratocumulus $(\mathrm{Sc})$, cumulus $(\mathrm{Cu})$, stratus-altostratus ( $\mathrm{St}-\mathrm{As})$, cumulonimbus-nimbostratus ( $\mathrm{Cb}-\mathrm{Ns})$, cirrocumulus-altocumulus ( $\mathrm{Cc}-\mathrm{Ac})$ and cirrus-cirrostratus $(\mathrm{Ci}-$ Cs). Data points (yellow dots) and box plots per okta with median (red line), interquartile range (blue box) and spread without outliers

\subsection{Cloud radiative effect}

\subsubsection{Longwave cloud effect}

By applying Eq. (1), the longwave cloud radiative effect (LCE) is calculated for Davos and Payerne and the six cloud classes separately. The dependence of the LCE on fractional cloud cover for the above-mentioned time period for all six cloud classes is shown for Davos in Fig. 3. The box plots in the figure show the median (red line), the interquartile range (blue box) and the values that are within 1.5 times the interquartile range of the box edges (black line) per okta cloud coverage.

Figure 3 shows a non-linear increase in the LCE with increasing fractional cloud coverage for some cloud classes. This non-linear increase is clearly observed for the cumulus type clouds $\mathrm{Cu}, \mathrm{Sc}$ and $\mathrm{Cc}-\mathrm{Ac}$, as well as for $\mathrm{St}-\mathrm{As}$. Clouds at different zenith angles in the sky have a stronger or weaker impact on the downward longwave radiation measured at the surface. In case the zenith angles of the clouds are not equally distributed in our analysed time period; this might be a reason for this non-linearity in the LCE. However, we have not analysed it in more detail yet and is subject of a future study. The cloud classes $\mathrm{St}-\mathrm{As}$ and $\mathrm{Cb}-\mathrm{Ns}$ are mainly present with a cloud coverage of 5 oktas and more. The median LCE value for $\mathrm{Ci}-\mathrm{Cs}$ in Davos and 8-okta cloud coverage at $53 \mathrm{Wm}^{-2}$ is clearly too high. Manually checked images indicate a misclassification of numerous cases as $\mathrm{Ci}-\mathrm{Cs}$ instead of a cloud 
type with a lower cloud base. A possible reason for the misclassification could be that the algorithm is trained with a data set from Payerne. In general, the greater the fractional cloud coverage, the more difficult it becomes to distinguish among cloud types. Table 1 gives an overview of the median values and their interquartile range of the LCE per okta cloud coverage for the six cloud classes for Davos and Payerne separately. The number of cases per cloud class and cloud fraction can be found in the appendix (Tables A1 and A2).

In Davos, the highest median LCE for a cloud coverage of 8 oktas is observed for the low-level cloud classes $\mathrm{Cb}-\mathrm{Ns}, \mathrm{St}-\mathrm{As}, \mathrm{Cu}$ and $\mathrm{Sc}$ with a maximum influence on the downward longwave radiation at the surface for $\mathrm{Cb}-\mathrm{Ns}$ $\left(67 \mathrm{Wm}^{-2}\right)$. The mid-level and thinner cloud class $\mathrm{Cc}-\mathrm{Ac}$ has a lower median LCE of $49 \mathrm{Wm}^{-2}$ for a cloud coverage of 8 oktas in comparison to the ones of low-level clouds. The median LCE value is clearly lower for the high-level cloud class $\mathrm{Ci}-\mathrm{Cs}$ and 7 oktas $\left(13 \mathrm{Wm}^{-2}\right)$. Also, for other cloud coverages median LCE values of the three low-level cloud types $\mathrm{Sc}, \mathrm{Cu}$ and $\mathrm{St}-\mathrm{As}$ stay in the same range.

Although the numbers differ between the two stations, the same pattern also holds for Payerne, namely that the lower the cloud, the higher the LCE value. Thus for Payerne, the four low-level cloud types ( $\mathrm{Sc}, \mathrm{Cu}, \mathrm{St}-\mathrm{As}$ and $\mathrm{Cb}-\mathrm{Ns}$ ) and 8-okta cloud coverages have median LCE values of $59-72 \mathrm{Wm}^{-2}$ (with interquartile ranges of maximum $\pm 10 \mathrm{Wm}^{-2}$ ). The median LCE value for the mid-level cloud class $\mathrm{Cc}-\mathrm{Ac}$ and 8 -okta cloud coverage is at $37 \mathrm{Wm}^{-2}$ clearly lower than the values for the low-level clouds and also in comparison with the same value in Davos. The median LCE value for the high-level cloud class $\mathrm{Ci}-\mathrm{Cs}$ and 8 oktas is around $22 \mathrm{Wm}^{-2}$. This value is only slightly lower for smaller cloud coverages.

The difference in the median LCE values between the two stations increases with decreasing cloud coverage. Except $\mathrm{Sc}$ and $\mathrm{Cb}-\mathrm{Ns}$, the LCE values are generally larger for the station Payerne in comparison with Davos. The difference might be partly due to a higher underestimation of the calculated LW cloud-free irradiances at Payerne. Another explanation for this difference might be that Payerne is located at a lower altitude level and thus the cloud-base temperature is higher, which leads to a larger emission of LW radiation. Some of the differences might also occur due to a limited number of cases in the specific groups (see Tables A1 and A2). Thus, some of the numbers have to be taken with caution.

\subsubsection{Shortwave cloud effect}

Table 2 summarises the median of the $\mathrm{SCE}_{\text {rel }}$ and the corresponding interquartile range for cloud coverages of one to 8 oktas and for the cloud classes for the two stations Davos and Payerne separately. The relative shortwave cloud radiative effect $\left(\mathrm{SCE}_{\text {rel }}\right)$ is calculated using Eq. (2). The number of occurrences per cloud class and cloud fraction are shown in Tables A1 and A2.

In Davos, the cloud type $\mathrm{Cb}-\mathrm{Ns}$, with $-90 \%$, has the largest attenuation for 8-okta cloud coverage. The second lowest $\mathrm{SCE}_{\text {rel }}$ value for 8-okta cloud coverage is observed for the cloud type $\mathrm{Cu}(-78 \%)$, followed by $\mathrm{Cc}-\mathrm{Ac}(-67 \%)$. The cloud classes St-As and Sc (both $-62 \%$ ) are almost in the same range. The uncertainty ranges given as interquartile ranges are for a fully covered sky up to $\pm 14 \%$. Also here no statistical values have been calculated for the high-level cloud class Ci-Cs and a cloud coverage of 8 oktas due to the same explanation as given in Sect. 3.2.1. However the median $\mathrm{SCE}_{\text {rel }}$ for $\mathrm{Ci}-\mathrm{Cs}$ and 1- to 7-okta cloud coverage is, in comparison to the low-level cloud classes, clearly less negative with values between 1 and $-9 \%$. In general, the median $\mathrm{SCE}_{\text {rel }}$ values become higher the smaller the cloud coverage is. This behaviour is obtained for all cloud classes.

In Payerne, a different order is observed in the lowest to the highest $\mathrm{SCE}_{\text {rel }}$ values for a cloud coverage of 8 oktas. The cloud class with the lowest values, and thus the largest effect on $\mathrm{SW}$ radiation, is again $\mathrm{Cb}-\mathrm{Ns}$ with $-82 \%$, followed by St-As $(-73 \%), \mathrm{Cu}(-66 \%)$ and $\mathrm{Sc}(-63 \%)$. The interquartile ranges are in a similar range to the ones for Davos. All of these four cloud classes are low-level cloud types and thicker clouds than the ones at a higher level. Therefore, it is reasonable to infer that these are the cloud classes with the greatest effect on the downward shortwave radiation. For Payerne, a clearly less negative median $\mathrm{SCE}_{\text {rel }}$ is observed for the midlevel cloud class $\mathrm{Cc}-\mathrm{Ac}$ and a cloud coverage of 8 oktas $(-47 \%)$ in comparison to low-level clouds. The highest median $\mathrm{SCE}_{\text {rel }}$ value for 8-okta cloud coverage is observed for the high-level cloud class $\mathrm{Ci}-\mathrm{Cs}(-29 \%)$.

The differences in $\mathrm{SCE}_{\text {rel }}$ values between Davos and Payerne are rather high for several cloud types and cloud coverages (e.g. $33 \%$ for $\mathrm{Cc}-\mathrm{Ac}$ and 3 oktas). An explanation for these larger differences, mainly for smaller cloud coverages, is the so-called cloud enhancement phenomenon, since the positive $\mathrm{SCE}_{\mathrm{rel}}$ values might increase the median of $\mathrm{SCE}_{\text {rel }}$. A cloud enhancement phenomenon describes an event in which more downward shortwave radiation is measured at the surface under cloudy conditions than expected under cloud-free conditions. Scattering at cloud edges leads to a focusing effect producing a local enhancement of the SW radiation.

For the calculation of the values in Table 2 different numbers of cases have been taken into account (see Appendix Tables A1 and A2); e.g. analysing the images that belong to the group St-As and 2 oktas in more detail leads to the result that for all 14 images for this specific group in Payerne the sun is covered by a cloud, whereas in Davos, only for around $20 \%$ of the 58 images is the sun occulted, and in the remaining $80 \%$ the sun is visible. As further discussed in Sect. 3.3.2, this visible or occulted sun can lead to a large difference in $\mathrm{SCE}_{\text {rel }}$ values. These larger differences in $\mathrm{SCE}_{\text {rel }}$ values between the two stations mainly occur when only a 
Table 1. Median and interquartile range of longwave cloud radiative effect values $\left[\mathrm{Wm}^{-2}\right]$ per okta for the two stations Davos (DAV) and Payerne (PAY) and six cloud classes stratocumulus $(\mathrm{Sc})$, cumulus $(\mathrm{Cu})$, stratus-altostratus (St-As), cumulonimbus-nimbostratus $(\mathrm{Cb}-\mathrm{Ns})$, cirrocumulus-altocumulus $(\mathrm{Cc}-\mathrm{Ac})$ and cirrus-cirrostratus $(\mathrm{Ci}-\mathrm{Cs})$.

\begin{tabular}{llrrrrrr}
\hline cc [okta $]$ & station & $\mathrm{Sc}\left[\mathrm{Wm}^{-2}\right]$ & $\mathrm{Cu}\left[\mathrm{Wm}^{-2}\right]$ & $\mathrm{St}-\mathrm{As}\left[\mathrm{Wm}^{-2}\right]$ & $\mathrm{Cb}-\mathrm{Ns}\left[\mathrm{Wm}^{-2}\right]$ & $\mathrm{Cc}-\mathrm{Ac}\left[\mathrm{Wm}^{-2}\right]$ & $\mathrm{Ci}-\mathrm{Cs}\left[\mathrm{Wm}{ }^{-2}\right]$ \\
\hline \multirow{2}{*}{1} & DAV & $8(2 ; 14)$ & $0(-2 ; 3)$ & $-(-)$ & $-(-)$ & $0(-3 ; 3)$ & $1(-3 ; 3)$ \\
& PAY & $8(2 ; 13)$ & $4(-2 ; 9)$ & $-(-)$ & $-(-)$ & $4(-1 ; 9)$ & $3(-2 ; 8)$ \\
2 & DAV & $9(5 ; 15)$ & $3(0 ; 6)$ & $10(5 ; 14)$ & $-(-)$ & $4(0 ; 8)$ & $3(1 ; 5)$ \\
\multirow{2}{*}{3} & PAY & $14(8 ; 2)$ & $13(6 ; 21)$ & $20(14 ; 30)$ & $-(-)$ & $13(5 ; 20)$ & $7(2 ; 13)$ \\
& DAV & $15(9 ; 21)$ & $8(3 ; 13)$ & $18(8 ; 24)$ & $-(-)$ & $5(1 ; 11)$ & $4(2 ; 7)$ \\
4 & PAY & $39(22 ; 53)$ & $21(14 ; 29)$ & $30(23 ; 36)$ & $-(-)$ & $18(10 ; 27)$ & $10(5 ; 16)$ \\
& DAV & $21(15 ; 29)$ & $14(9 ; 20)$ & $23(17 ; 28)$ & $-(-)$ & $9(4 ; 15)$ & $7(3 ; 11)$ \\
5 & PAY & $36(25 ; 47)$ & $26(19 ; 32)$ & $38(31 ; 46)$ & $66(51 ; 75)$ & $23(15 ; 33)$ & $12(8 ; 18)$ \\
& DAV & $27(18 ; 35)$ & $22(18 ; 28)$ & $23(15 ; 32)$ & $54(46 ; 64)$ & $15(9 ; 21)$ & $9(5 ; 13)$ \\
6 & PAY & $37(27 ; 47)$ & $29(22 ; 34)$ & $37(32 ; 49)$ & $57(50 ; 68)$ & $27(18 ; 37)$ & $15(10 ; 20)$ \\
& DAV & $35(26 ; 4)$ & $34(26 ; 47)$ & $32(22 ; 44)$ & $51(42 ; 60)$ & $22(16 ; 29)$ & $9(5 ; 14)$ \\
7 & PAY & $41(31 ; 52)$ & $36(28 ; 44)$ & $41(32 ; 64)$ & $58(50 ; 66)$ & $32(22 ; 42)$ & $18(11 ; 24)$ \\
& DAV & $48(39 ; 56)$ & $57(50 ; 63)$ & $47(33 ; 56)$ & $56(48 ; 64)$ & $32(24 ; 41)$ & $13(8 ; 16)$ \\
8 & PAY & $47(36 ; 56)$ & $54(33 ; 65)$ & $65(50 ; 73)$ & $57(49 ; 64)$ & $36(28 ; 46)$ & $20(14 ; 27)$ \\
& DAV & $61(54 ; 67)$ & $63(58 ; 68)$ & $65(56 ; 71)$ & $67(61 ; 73)$ & $49(40 ; 57)$ & $-(-)$ \\
& PAY & $59(49 ; 67)$ & $62(58 ; 72)$ & $72(67 ; 76)$ & $63(54 ; 70)$ & $37(26 ; 51)$ & $22(17 ; 28)$ \\
\hline
\end{tabular}

Table 2. Median and interquartile range of relative shortwave cloud radiative effect values [\%] per okta for the two stations Davos (DAV) and Payerne (PAY) and six cloud classes stratocumulus $(\mathrm{Sc})$, cumulus $(\mathrm{Cu})$, stratus-altostratus (St-As), cumulonimbus-nimbostratus $(\mathrm{Cb}-\mathrm{Ns})$, cirrocumulus-altocumulus $(\mathrm{Cc}-\mathrm{Ac})$ and cirrus-cirrostratus $(\mathrm{Ci}-\mathrm{Cs})$.

\begin{tabular}{llrrrrrr}
\hline cc [okta] & station & Sc [\%] & Cu [\%] & St-As $[\%]$ & Cb-Ns $[\%]$ & Cc-Ac [\%] & Ci-Cs [\%] \\
\hline \multirow{2}{*}{1} & DAV & $4(-1 ; 5)$ & $1(-1 ; 4)$ & $-(-)$ & $-(-)$ & $1(-1 ; 3)$ & $1(-2 ; 4)$ \\
& PAY & $-6(-28 ; 5)$ & $1(-29 ; 9)$ & $-(-)$ & $-(-)$ & $3(-15 ; 9)$ & $-1(-9 ; 4)$ \\
2 & DAV & $2(-22 ; 11)$ & $3(-5 ; 7)$ & $10(6 ; 15)$ & $-(-)$ & $3(-4 ; 7)$ & $1(-3 ; 5)$ \\
& PAY & $-7(-37 ; 7)$ & $-13(-52 ; 12)$ & $-37(-42 ;-15)$ & $-(-)$ & $-19(-50 ; 10)$ & $-5(-18 ; 5)$ \\
3 & DAV & $-4(-49 ; 13)$ & $5(-23 ; 10)$ & $15(11 ; 27)$ & $-(-)$ & $3(-15 ; 10)$ & $-1(-6 ; 5)$ \\
4 & PAY & $-55(-68 ;-39)$ & $-28(-56 ; 12)$ & $-32(-44 ;-17)$ & $-(-)$ & $-30(-51 ; 6)$ & $-9(-23 ; 4)$ \\
& DAV & $-14(-51 ; 14)$ & $-5(-51 ; 12)$ & $19(-18 ; 32)$ & $-(-)$ & $0(-41 ; 11)$ & $-4(-17 ; 5)$ \\
5 & PAY & $-60(-66 ;-51)$ & $-43(-59 ; 2)$ & $-42(-52 ;-27)$ & $-57(-72 ;-37)$ & $-29(-48 ;-1)$ & $-10(-25 ; 3)$ \\
& DAV & $-25(-53 ; 13)$ & $-44(-64 ;-4)$ & $-26(-50 ; 2)$ & $-60(-72 ;-43)$ & $-16(-51 ; 11)$ & $-6(-18 ; 4)$ \\
6 & PAY & $-54(-63 ;-44)$ & $-49(-61 ;-23)$ & $-31(-53 ;-21)$ & $-54(-77 ;-29)$ & $-28(-44 ;-1)$ & $-12(-26 ;-1)$ \\
& DAV & $-38(-55 ;-6)$ & $-60(-70 ;-48)$ & $-39(-54 ;-11)$ & $-63(-72 ;-45)$ & $-16(-48 ; 11)$ & $-6(-16 ; 3)$ \\
7 & PAY & $-50(-60 ;-39)$ & $-42(-59 ;-8)$ & $-39(-62 ;-20)$ & $-63(-76 ;-39)$ & $-25(-41 ; 1)$ & $-21(-35 ;-9)$ \\
& DAV & $-45(-58 ;-26)$ & $-71(-78 ;-61)$ & $-45(-57 ;-26)$ & $-66(-78 ;-52)$ & $-34(-54 ;-5)$ & $-9(-17 ; 0)$ \\
8 & PAY & $-48(-58 ;-35)$ & $-59(-68 ;-30)$ & $-61(-71 ;-46)$ & $-64(-77 ;-43)$ & $-25(-39 ; 0)$ & $-21(-34 ;-8)$ \\
& DAV & $-62(-72 ;-49)$ & $-78(-85 ;-70)$ & $-62(-75 ;-48)$ & $-90(-95 ;-82)$ & $-67(-78 ;-55)$ & $-(-)$ \\
& PAY & $-63(-76 ;-51)$ & $-66(-79 ;-57)$ & $-73(-79 ;-65)$ & $-82(-89 ;-71)$ & $-47(-63 ;-31)$ & $-29(-41 ;-16)$ \\
\hline
\end{tabular}

limited number of images are available. Therefore, some of the $\mathrm{SCE}_{\text {rel }}$ values have to be taken with caution.

Figure 4 shows a density plot of the dependence of $\mathrm{SCE}_{\text {rel }}$ on fractional cloud coverage in Davos for the mid-level cloud class Cc-Ac. Mainly at larger cloud coverages, there is a range of higher densities of data points of $\mathrm{SCE}_{\text {rel }}$ values between -80 and $-60 \%$. However, there is another stronger local maximum in the density distribution which shows positive $\mathrm{SCE}_{\text {rel }}$ values of up to $20 \%$ at smaller cloud coverages. There are also some cases in which the $\mathrm{SCE}_{\text {rel }}$ values reach up to $40 \%$. This enhancement of the downward shortwave radiation measured at the surface in the presence of clouds can also be detected in the low-level cloud classes.

If we define a cloud radiative enhancement with a minimum SCE $\mathrm{Sel}_{\text {rel }}+5 \%$, in Davos 69941 out of 495473 cloud cases are detected as cloud enhancement, which is $14 \%$ of the analysed cases. The largest contribution stems from the cloud class $\mathrm{Cc}-\mathrm{Ac}$ in $32 \%$ of the cases, followed by $\mathrm{Cu}$ in $27 \%$, Sc $(21 \%)$, St-As (10\%) and Ci-Cs (10\%). The percentage of cases of observed cloud enhancement due to the presence of $\mathrm{Cb}-\mathrm{Ns}$ are negligibly small at $0.2 \%$. Thus, the mid-level cloud class Cc-Ac leads to most of the cases of cloud enhancement. However, checking for the cloud types 


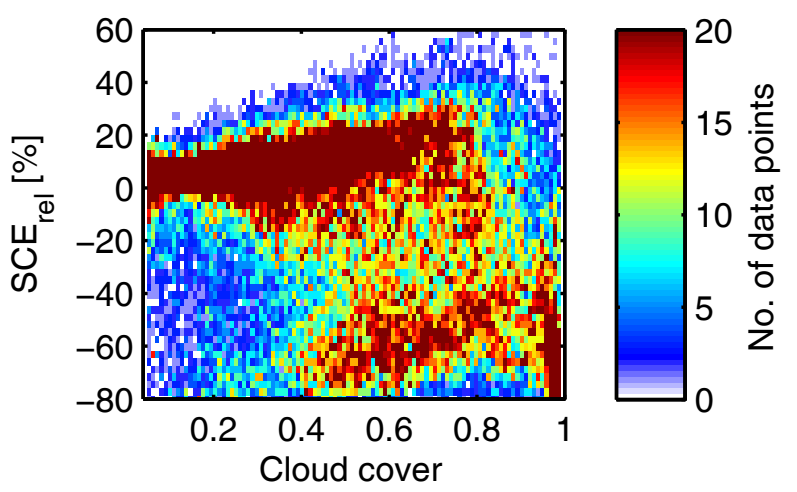

Figure 4. Density distribution of the dependence of $\mathrm{SCE}_{\mathrm{rel}}$ on cloud coverage for Davos for mid-level clouds (Cc-Ac). The density colour distribution represents the number of data points.

that produce $\mathrm{SCE}_{\text {rel }}$ values of more than $40 \%$ leads to another order of contribution of different cloud classes.

In Davos, 2238 cases $(0.5 \%$ of the cloud data) are observed with $\mathrm{SCE}_{\text {rel }}$ values of $40 \%$ and above. Here the contribution of the two low-level cloud classes St-As (43\%) and Sc $(40 \%)$ is greater than the contribution of the mid-level cloud class Cc-Ac (13\%). These are also the cloud types that mainly contribute to high positive $\mathrm{SCE}_{\text {rel }}$ values. The contributions of $\mathrm{Ci}-\mathrm{Cs}(2 \%), \mathrm{Cu}(1 \%)$ and $\mathrm{Cb}-\mathrm{Ns}(0.2 \%)$ are negligibly small.

In Payerne, in $10 \%$ of the 88155 cloud cases a cloud enhancement of more than $5 \% \mathrm{SCE}_{\text {rel }}$ is observed. Also here, most of the cloud enhancement cases are Cc-Ac in $42 \%$ of the cases, followed by $\mathrm{Ci}-\mathrm{Cs}$ with a $30 \%$ contribution. $\mathrm{Cu}$ only makes a contribution of $19 \%$ to the total 8793 cases of cloud enhancement greater than $5 \% \mathrm{SCE}_{\text {rel }}$. In $8 \%$ of the cloud enhancement cases in Payerne a Sc cloud is responsible. The number of cloud enhancement cases for the cloud classes $\mathrm{Cb}-\mathrm{Ns}(1 \%)$ and $\mathrm{St}-\mathrm{As}(0.2 \%)$ are negligibly small.

A cloud enhancement of at least $40 \% \mathrm{SCE}_{\text {rel }}$ in Payerne is detected only for 281 cases in total in the studied time period. More than half of these 281 cases are $\mathrm{Cc}-\mathrm{Ac}(62 \%)$, followed by $\mathrm{Sc}(19 \%)$ and $\mathrm{Cu}(9 \%)$. Only a few cases are $\mathrm{Cb}-\mathrm{Ns}(6 \%)$ and $\mathrm{Ci}-\mathrm{Cs}(4 \%)$. For $\mathrm{St}-\mathrm{As}$ clouds there is no case observed with a cloud enhancement of more than $40 \%$ $\mathrm{SCE}_{\text {rel }}$.

Schade et al. (2007) also showed that altocumulus is the cloud type that produces most of the downward solar cloud enhancement. They demonstrated that altocumulus clouds can be responsible for temporary enhancements of up to $500 \mathrm{Wm}^{-2}$. In our data, in Davos the maximum cloud enhancement with $\mathrm{Cc}-\mathrm{Ac}$ is a SCE value of $477 \mathrm{Wm}^{-2}$ and in Payerne it is $440 \mathrm{Wm}^{-2}$ under $\mathrm{Ci}-\mathrm{Cs}$ conditions. Schade et al. (2007) showed that the largest cloud enhancements can be registered at near-overcast situations. However, our data show a maximum in cloud enhancement cases for a fractional cloud coverage of 3 to 4 oktas in Davos and 1 to 3 oktas in Payerne.

The manual analysis of the cloud camera images with cloud enhancement leads to the result that in most of the cases there is a low solar zenith angle. Additionally, it has been observed that in cloud enhancement cases the sun is either in the vicinity of the cloud or covered with a thin cloud layer. Several studies (e.g. Robinson, 1966; Schade et al., 2007; Thuillier et al., 2013; Calbo et al., 2017) show the influence of the magnitude of cloud enhancement events and its duration. To compare our results with these analyses on the duration of cloud enhancement events, the resolution of 1-min images needs to be increased to the seconds range and will be the subject of a subsequent study.

\subsubsection{Total cloud effect}

The total cloud radiative effect (TCE) is calculated as the sum of the LCE and SCE (Eq. 1). The calculated median TCE values and the corresponding interquartile range for cloud coverages of one to 8 oktas and the cloud classes for the two stations Davos and Payerne are summarised in Table 3 separately. For the calculation of TCE, the absolute values of SCE are taken into account and Eq. (2) is not applied. The TCE values are mainly to get an idea of whether the SCE or the LCE is the prevailing contributor to the TCE during the daytime.

During the daytime, the SCE values are the main contribution to the TCE for all cloud classes and cloud coverages of 6 to 8 oktas and the two stations, Davos and Payerne. For the low-level cloud type $\mathrm{Cb}-\mathrm{Ns}$, the TCE values are negative for all okta cloud coverages. Thus, during the daytime, the SCE is the main contributor to TCE for this cloud class. The smaller the cloud coverage is, the less negative the TCE values are. This behaviour can be seen for all cloud types and both stations. One reason for these positive values with smaller cloud coverages might be the cloud enhancement events as described in Sect. 3.2.2. Other reasons might be the uncertainty in the cloud-type detection algorithm as well as a larger uncertainty in SCE values with a larger SZA.

\subsection{Sensitivity analysis}

\subsubsection{Longwave cloud effect}

As described in Sect. 3.2.1, the spread of the data within one okta cloud coverage is large. This large spread can be explained, for example, by the misclassification of the cloud type as well as by the uncertainty of the detection of cloud fraction of \pm 1 okta (Wacker et al., 2015). Additionally, other parameters are responsible for this uncertainty. Thus, in a sensitivity analysis the influence of IWV and CBH is analysed. Figure 5 shows the dependence of LCE on changes of IWV for all low-level clouds ( $\mathrm{Sc}, \mathrm{Cu}, \mathrm{St}-\mathrm{As}$ and $\mathrm{Cb}-\mathrm{Ns}$ ) and a cloud coverage of 8 oktas for Davos. The low-level clouds 
Table 3. The median and interquartile range of the total cloud radiative effect $\left[\mathrm{Wm}^{-2}\right]$ per okta for the two stations Davos (DAV) and Payerne (PAY) and the six cloud classes stratocumulus $(\mathrm{Sc})$, cumulus $(\mathrm{Cu})$, stratus-altostratus $(\mathrm{St}-\mathrm{As})$, cumulonimbus-nimbostratus $(\mathrm{Cb}-$ $\mathrm{Ns})$, cirrocumulus-altocumulus (Cc-Ac) and cirrus-cirrostratus (Ci-Cs).

\begin{tabular}{llrrrrrr}
\hline cc $[\mathrm{okta}]$ & station & $\mathrm{Sc}\left[\mathrm{Wm}^{-2}\right]$ & $\mathrm{Cu}\left[\mathrm{Wm}^{-2}\right]$ & $\mathrm{St}-\mathrm{As}\left[\mathrm{Wm}^{-2}\right]$ & $\mathrm{Cb}-\mathrm{Ns}\left[\mathrm{Wm}^{-2}\right]$ & $\mathrm{Cc}-\mathrm{Ac}\left[\mathrm{Wm}{ }^{-2}\right]$ & $\mathrm{Ci}-\mathrm{Cs}\left[\mathrm{Wm}{ }^{-2}\right]$ \\
\hline \multirow{2}{*}{1} & DAV & $26(-2 ; 39)$ & $7(-7 ; 23)$ & $-(-)$ & $-(-)$ & $5(-4 ; 16)$ & $7(-9 ; 24)$ \\
& PAY & $-14(-78 ; 24)$ & $9(-88 ; 52)$ & $-(-)$ & $-(-)$ & $17(-55 ; 55)$ & $-3(-33 ; 27)$ \\
2 & DAV & $20(-80 ; 66)$ & $17(-22 ; 45)$ & $71(30 ; 84)$ & $-(-)$ & $20(-16 ; 46)$ & $7(-14 ; 31)$ \\
& PAY & $-21(-156 ; 59)$ & $-42(-217 ; 87)$ & $-69(-98 ; 16)$ & $-(-)$ & $-49(-136 ; 59)$ & $-18(-72 ; 36)$ \\
3 & DAV & $-5(-197 ; 88)$ & $35(-106 ; 73)$ & $99(51 ; 129)$ & $-(-)$ & $23(-65 ; 66)$ & $0(-28 ; 27)$ \\
& PAY & $-130(-215 ;-78)$ & $-113(-289 ; 95)$ & $-61(-88 ; 18)$ & $-(-)$ & $-72(-148 ; 34)$ & $-38(-102 ; 40)$ \\
4 & DAV & $-42(-216 ; 97)$ & $-17(-239 ; 99)$ & $87(-64 ; 137)$ & $-(-)$ & $5(-182 ; 85)$ & $-15(-67 ; 31)$ \\
& PAY & $-146(-244 ;-91)$ & $-198(-360 ; 51)$ & $-92(-214 ;-41)$ & $-74(-92 ;-33)$ & $-76(-169 ; 20)$ & $-46(-127 ; 29)$ \\
5 & DAV & $-82(-247 ; 94)$ & $-166(-360 ;-6)$ & $-74(-145 ; 27)$ & $-235(-281 ;-130)$ & $-79(-258 ; 95)$ & $-24(-82 ; 32)$ \\
& PAY & $-154(-270 ;-87)$ & $-282(-419 ;-122)$ & $-97(-189 ;-36)$ & $-82(-128 ;-7)$ & $-84(-186 ; 18)$ & $-62(-149 ; 11)$ \\
6 & DAV & $-139(-308 ; 4)$ & $-283(-421 ;-143)$ & $-105(-186 ;-20)$ & $-153(-272 ;-81)$ & $-87(-257 ; 95)$ & $-30(-88 ; 26)$ \\
& PAY & $-149(-255 ;-80)$ & $-269(-368 ;-29)$ & $-135(-193 ;-67)$ & $-104(-237 ;-44)$ & $-82(-177 ; 32)$ & $-121(-211 ;-40)$ \\
7 & DAV & $-218(-352 ;-86)$ & $-343(-507 ;-194)$ & $-145(-258 ;-63)$ & $-205(-328 ;-116)$ & $-175(-316 ;-11)$ & $-49(-106 ; 7)$ \\
& PAY & $-155(-262 ;-86)$ & $-292(-398 ;-76)$ & $-157(-240 ;-110)$ & $-121(-219 ;-59)$ & $-76(-198 ; 32)$ & $-122(-217 ;-38)$ \\
8 & DAV & $-335(-462 ;-210)$ & $-376(-543 ;-247)$ & $-247(-394 ;-145)$ & $-301(-443 ;-189)$ & $-315(-462 ;-192)$ & \\
& PAY & $-240(-372 ;-141)$ & $-466(-572 ;-322)$ & $-250(-387 ;-159)$ & $-187(-313 ;-115)$ & $-223(-354 ;-95)$ & $-183(-275 ;-93)$ \\
\hline
\end{tabular}

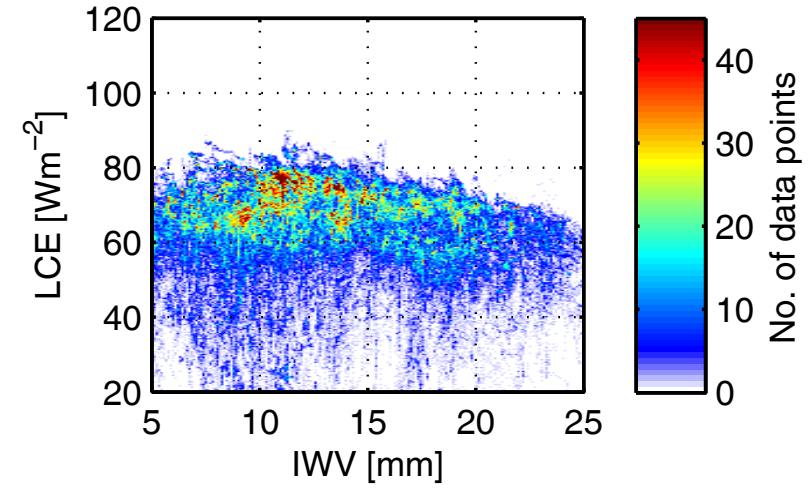

Figure 5. Dependence of the LCE on integrated water vapour (IWV) for Davos and cloud coverage of 8 oktas for low-level clouds ( $\mathrm{Sc}, \mathrm{Cu}, \mathrm{St}-\mathrm{As}, \mathrm{Cb}-\mathrm{Ns}$ ) shown as a density plot.

have been taken together, since on the one hand the LCE values for all the four low-level cloud classes are in a similar range and on the other hand there is considerable uncertainty in distinguishing the different cloud classes with increasing cloud coverage using the sky camera images.

Figure 5 shows a slightly negative trend between the LCE and IWV. The higher the water vapour content in the atmosphere is, the lower the values of the LCE are. Although the trend is statistically not significant, this negative trend is detected for different cloud classes, fractional cloud coverages and for the two stations Davos and Payerne.

The observed relationship between the LCE and IWV was analysed by modelling a standard situation with the moderate resolution atmospheric transmission model MODTRAN5 (Berk et al., 2005). We assume a standard atmosphere profile for midlatitude summer and winter separately with 50 altitude levels. We also assume no aerosol extinction throughout the atmosphere due to its negligible influence on the

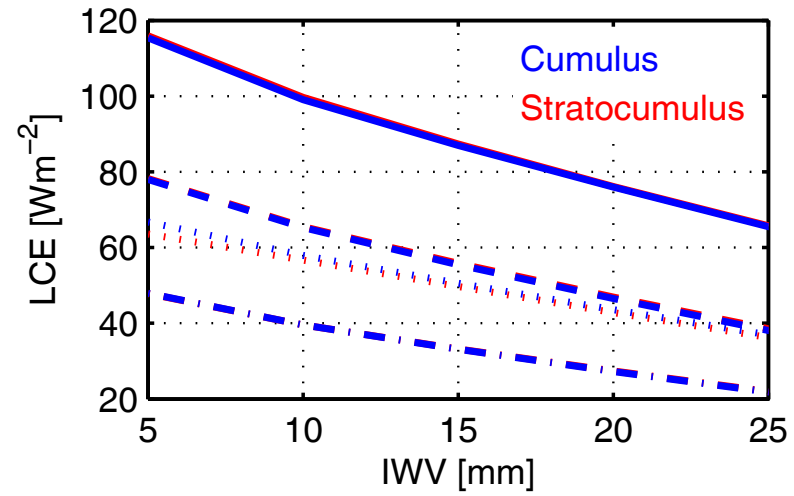

Figure 6. Dependence of the LCE on integrated water vapour (IWV) modelled for cumulus (blue) and stratocumulus (red) clouds. Solid line: summer standard atmosphere (SSA) and cloud-base height $(\mathrm{CBH})$ of $1 \mathrm{~km}$. Dotted line: $\mathrm{SSA}, \mathrm{CBH}=5 \mathrm{~km}$. Dashed line: winter standard atmosphere (WSA), $\mathrm{CBH}=1 \mathrm{~km}$. Dashed-dotted line: $\mathrm{WSA}, \mathrm{CBH}=5 \mathrm{~km}$.

longwave radiation (Ramanathan et al., 2001; di Sarra et al., 2011). The default cloud parameters that have been taken for the model are for cumulus, a cloud thickness of $2.34 \mathrm{~km}$ (stratocumulus: $1.34 \mathrm{~km}$ ), a cloud extinction coefficient at $0.55 \mu \mathrm{m}$ of $92.6 \mathrm{~km}^{-1}\left(38.7 \mathrm{~km}^{-1}\right)$ and a cloud liquid water vertical column density of $1.6640 \mathrm{~kg} \mathrm{~m}^{-2}\left(0.2165 \mathrm{~kg} \mathrm{~m}^{-2}\right)$. The input IWV values have been changed between 5 and $25 \mathrm{~mm}$. The output of the model is shown in Fig. 6 for cumulus (blue) and stratocumulus (red).

The mean values of the observed dependence of the LCE on IWV (Fig. 5) agree well with the mean values of the modelled dependence of the two aforementioned parameters, LCE and IWV (Fig. 6). The model also shows that more water vapour in the atmosphere results in lower LCE values for the two cloud types. The influence is smaller because in cases 


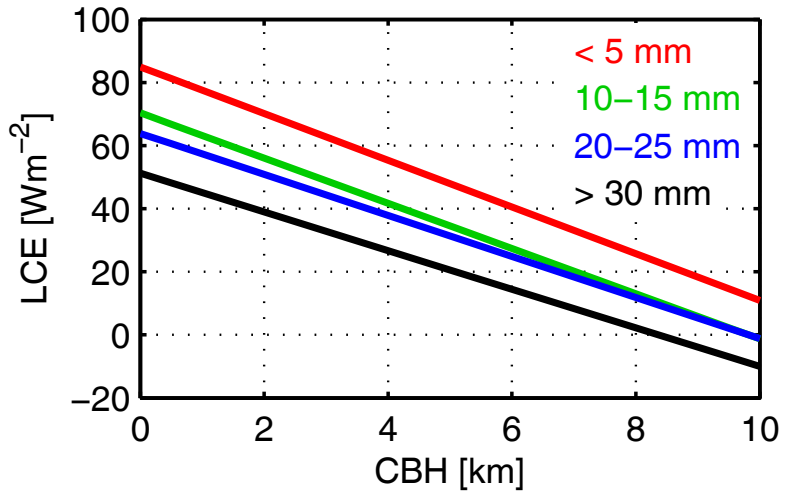

Figure 7. Dependence of the LCE on cloud-base height (CBH) for Payerne and linear regression lines of the following measured IWV ranges: red: $<5 \mathrm{~mm}$, green: $10-15 \mathrm{~mm}$, blue: $20-25 \mathrm{~mm}$ and black: $>30 \mathrm{~mm}$

in which there is more water vapour in the atmosphere, the cloud is shielded and the longwave radiation measured at the Earth's surface partially comes from the water vapour and partially from the cloud itself. In the case of less IWV in the atmosphere, the influence of the cloud is greater and consequently the LCE is also higher. $\mathrm{Cu}$ and $\mathrm{Sc}$ show similar behaviour in the model, which might be explained by similar microphysical characteristics of the two cloud types.

Another parameter which might explain the large spread in the LCE within one cloud cover range is the CBH. This analysis has only been performed for the data set in Payerne, because it is only at this location that we measure the $\mathrm{CBH}$ with a ceilometer. The observed mean dependence of LCE on $\mathrm{CBH}$ and IWV is shown in Fig. 7. The colours represent different ranges of IWV.

Figure 7 shows that the lower the $\mathrm{CBH}$, the higher the LCE. This pattern can be explained by the fact that a lower $\mathrm{CBH}$ is a proxy for a higher cloud-base temperature, which in turn leads to higher thermal emissions. The modelling of these cases with the radiative transfer model MODTRAN5 with the same standard conditions as explained above confirms this assumption. The influence of $\mathrm{CBH}$ on downward longwave radiation has been analysed in more detail in Viudez-Mora et al. (2015). Figure 7 also shows that the more water vapour in the atmosphere, the lower the LCE.

Another important parameter in the LCE discussion for thin clouds is the optical depth of clouds (Viudez-Mora et al., 2015). However, since no data on this parameter are available, it is not discussed in the current study.

\subsubsection{Shortwave cloud effect}

In Sect. 3.2.2 it has been shown that, mainly for small cloud coverages, the majority of the cases show a $\mathrm{SCE}_{\text {rel }}$ value of around $0 \%$. In order to understand these values and the difference to the situation when the $\mathrm{SCE}_{\text {rel }}$ value is in a strong negative range, we analysed the images to determine whether

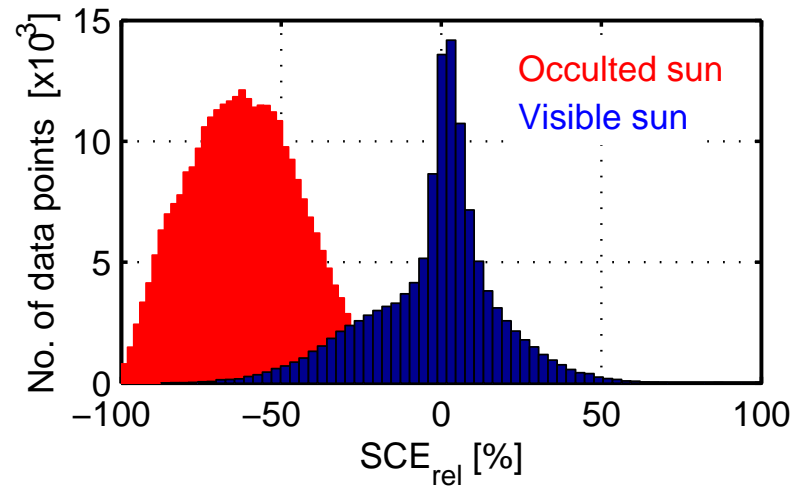

Figure 8. Distribution of $\mathrm{SCE}_{\mathrm{rel}}$ values for Davos for low-level clouds ( $\mathrm{Sc}, \mathrm{Cu}, \mathrm{St}-\mathrm{As}, \mathrm{Cb}-\mathrm{Ns}$ ). The measured direct $\mathrm{SW}$ radiation is below (red) or above (blue) a threshold of $120 \mathrm{Wm}^{-2}$.

the sun is directly covered by a cloud. Whether the sun is occulted or visible is decided on the basis of measured data on direct solar irradiance. In cases in which the value of the direct solar irradiance measurement of $120 \mathrm{Wm}^{-2}$ per time step is exceeded, it is assumed that the sun is not covered by a cloud. This reference value of $120 \mathrm{Wm}^{-2}$ is defined by the World Meteorological Organization (CIMO, 2014). Figure 8 shows the distribution of $\mathrm{SCE}_{\text {rel }}$ values of all data points in Davos for low-level clouds ( $\mathrm{Sc}, \mathrm{Cu}, \mathrm{St}-\mathrm{As}$ and $\mathrm{Cb}-\mathrm{Ns}$ ). This distribution shows two peaks, one at around $\mathrm{SCE}_{\text {rel }}$ values of $0 \%$ and the other one at $\mathrm{SCE}_{\text {rel }}$ values of $-65 \%$.

If the cases are now divided when the measured direct radiation value is below $120 \mathrm{Wm}^{-2}$ (red) and above this threshold (blue), the result is two separate histograms as shown in Fig. 8. The red histogram shows the situations in which the cloud has a substantial effect on decreasing the measured shortwave radiation at the surface, which results in a more negative $\mathrm{SCE}_{\text {rel }}$ value. The peak from the blue histogram is from around zero to slightly positive values. There the sun is visible and thus the cloud does not diminish the direct radiation but rather increases the diffuse radiation measured at the surface.

\section{Conclusions and outlook}

The current study analyses the cloud radiative effect depending on cloud type and cloud fraction at two stations in Switzerland over a time period of 3 to 5 years.

We have shown that low-level cloud types like cumulus, stratocumulus, stratus-altostratus and cumulonimbusnimbostratus have greater longwave cloud radiative effect values with median values of $59-72 \mathrm{Wm}^{-2}$ than mid-level cirrocumulus-altocumulus clouds $\left(37-49 \mathrm{Wm}^{-2}\right)$. Our measurements show that most low-level cloud types have a longwave cloud effect at the surface in a similar range. The differences in the longwave cloud radiative effect between the two stations Davos and Payerne is for a cloud coverage of 8 ok- 
tas up to $12 \mathrm{Wm}^{-2}$ and increases (up to around $25 \mathrm{Wm}^{-2}$ ) with smaller fractional cloud coverage. Some of these differences might be affected by misclassifications of the cloud algorithm.

Our study confirmed that the cloud-base height and the fractional cloud coverage have an influence on the range of the LCE. The higher the cloud coverage, the greater the LCE and the lower the cloud-base height, the larger the LCE.

We also showed that there is a negative dependence of the LCE on integrated water vapour. A similar trend was observed using radiative transfer modelling studies, as well as by Wacker et al. (2011).

Low-level clouds have a greater effect on the $\mathrm{SCE}_{\text {rel }}$ (up to $-90 \%$ for $\mathrm{Cb}-\mathrm{Ns}$ ) than mid- (up to $-67 \%$ ) or highlevel clouds $(-29 \%)$. However, this is not only influenced by cloud parameters but also depends on whether the sun is visible or occulted. There are two different distributions depending on whether the measured direct SW radiation exceeds a threshold of $120 \mathrm{Wm}^{-2}$ or not: one has its maximum at around $-65 \%$ (occulted sun) and the other one around $0 \%$ (visible sun).

Our data show that in 14 and $10 \%$ of the cases in Davos and Payerne respectively a shortwave cloud radiative enhancement of at least $5 \%$ is observed. We show that $\mathrm{Cc}-\mathrm{Ac}$ is the cloud type that is responsible for at least one-third of the cloud enhancement cases in Davos and Payerne.
In the current analysis, only one cloud type per cloud camera image is defined. A step forward would be to distinguish between different cloud types per image. This detection of different cloud types per image is already an intermediate step in our algorithm. At the current state the cloud type with most of the hits is determined. A further step would be to not only get the most probable cloud type per image but also to obtain the different cloud types per image as output. Thereafter, a more accurate analysis considering the influence of the cloud type on the cloud radiative effect would be possible.

To further minimise the number of misclassifications, for a future study it might be enough to distinguish between low-, mid- and high-level clouds instead of cloud types. This would also increase the number of cases per cloud type and cloud fraction and might decrease the uncertainty of the cloud-type detection algorithm. However, it would also decrease the variety in the cloud information.

Another step forward might be to combine different cloud detection instruments. A new observing system (thermal infrared cloud camera) has been developed in order to collect all-sky cloud information from day- and nighttime measurements. This expansion of the data set to nighttime information is necessary for climate-monitoring applications.

Data availability. All data are available from the corresponding author on request. 


\section{Appendix A: Appendix}

Table A1. Number of cases per okta for Davos and six cloud classes stratocumulus $(\mathrm{Sc})$, cumulus $(\mathrm{Cu})$, stratus-altostratus ( $\mathrm{St}-\mathrm{As})$, cumulonimbus-nimbostratus $(\mathrm{Cb}-\mathrm{Ns})$, cirrocumulus-altocumulus $(\mathrm{Cc}-\mathrm{Ac})$ and cirrus-cirrostratus $(\mathrm{Ci}-\mathrm{Cs})$.

\begin{tabular}{lrrrrrr}
\hline cc [okta] & $\mathrm{Sc}$ & $\mathrm{Cu}$ & $\mathrm{St}-\mathrm{As}$ & $\mathrm{Cb}-\mathrm{Ns}$ & $\mathrm{Cc}-\mathrm{Ac}$ & $\mathrm{Ci}-\mathrm{Cs}$ \\
\hline 1 & 43 & 31875 & - & - & 23330 & 1687 \\
2 & 1449 & 19027 & 58 & - & 10295 & 3277 \\
3 & 4617 & 7820 & 84 & - & 10888 & 7379 \\
4 & 8492 & 2613 & 455 & - & 11016 & 7747 \\
5 & 12834 & 1431 & 3743 & 50 & 9165 & 5331 \\
6 & 13708 & 614 & 11735 & 424 & 8165 & 1991 \\
7 & 17311 & 909 & 37899 & 1819 & 6272 & 608 \\
8 & 21305 & 5072 & 165187 & 11492 & 6180 & - \\
\hline
\end{tabular}

Table A2. Number of cases per okta for Payerne and six cloud classes stratocumulus $(\mathrm{Sc})$, cumulus $(\mathrm{Cu})$, stratus-altostratus ( $\mathrm{St}-\mathrm{As})$, cumulonimbus-nimbostratus ( $\mathrm{Cb}-\mathrm{Ns})$, cirrocumulusaltocumulus ( $\mathrm{Cc}-\mathrm{Ac})$ and cirrus-cirrostratus ( $\mathrm{Ci}-\mathrm{Cs})$.

\begin{tabular}{lrrrrrr}
\hline cc [okta] & $\mathrm{Sc}$ & $\mathrm{Cu}$ & $\mathrm{St}-\mathrm{As}$ & $\mathrm{Cb}-\mathrm{Ns}$ & $\mathrm{Cc}-\mathrm{Ac}$ & $\mathrm{Ci}-\mathrm{Cs}$ \\
\hline 1 & 731 & 1660 & - & - & 3382 & 5838 \\
2 & 177 & 1468 & 14 & - & 1559 & 2562 \\
3 & 32 & 1023 & 54 & - & 1624 & 1450 \\
4 & 235 & 576 & 76 & 25 & 1875 & 786 \\
5 & 792 & 217 & 73 & 75 & 2005 & 459 \\
6 & 1939 & 53 & 76 & 159 & 1542 & 470 \\
7 & 5293 & 14 & 75 & 518 & 729 & 719 \\
8 & 27091 & 29 & 7539 & 12530 & 142 & 469 \\
\hline
\end{tabular}


Competing interests. The authors declare that they have no conflict of interest.

Acknowledgements. This research was carried out within the framework of the project A Comprehensive Radiation Flux Assessment (CRUX) financed by MeteoSwiss. Alexander Haefele from MeteoSwiss provided the ceilometer data. The authors thank Josep Calbó and the two anonymous referees for their constructive comments.

Edited by: Vassilis Amiridis

Reviewed by: Josep Calbó and two anonymous referees

\section{References}

Allan, R. P.: Combining satellite data and models to estimate cloud radiative effect at the surface and in the atmosphere, Meterol. Appl., 18, 324-333, https://doi.org/10.1002/met.285, 2011.

Allan, R. P., Slingo, A., Milton, S. F., and Brooks, M. E.: Evaluation of the met office global forecast model using geostationary earth radiation budget (gerb) data, Q. J. Roy. Meteor. Soc., 133, $1993-$ 2010, https://doi.org/10.1002/qj.166, 2007.

Alonso, J., Batlles, F. J., López, G., and Ternero, A.: Sky camera imagery processing based on a sky classification using radiometric data, Energy, 68, 599-608, https://doi.org/10.1016/j.energy.2014.02.035, 2014.

Berk, A., Anderson, G. P., Acharya, P. K., Bernstein, L. S., Muratov, L., Lee, J., Fox, M. J., Adler-Golden, S. M., Chetwynd, J. H., Hoke, M. L., Lockwood, R. B., Cooley, T. W., and Gardner, J. A.: Modtran5: a reformulated atmospheric band model with auxiliary species and practical multiple scattering options, SPIE processing, https://doi.org/10.1117/12.578758, 2005.

Bevis, M., Businger, S., Herring, T. A., Rocken, C., Anthes, R. A., and Ware, R. H.: GPS meteorology: Remote sensing of atmospheric water vapour using the global positioning system, J. Geophys. Res., 97, 15787-15801, https://doi.org/10.1029/92JD01517, 1992.

Bony, S., Colman, R., Kattsov, V. M., Allan, R. P., Bretherton, C. S., Dufresne, J.-L., Hall, A., Hallegatte, S., Holland, M. M., Ingram, W., Randall, D. A., Soden, B. J., Tselioudis, G., and Webb, M. J.: How well do we understand and evaluate climate change feedback processes?, J. Climate, 19, 3445-3482, https://doi.org/10.1175/JCLI3819.1, 2006.

Boucher, O., Randall, D., Artaxo, P., Bretherton, C., Feingold, G., Forster, P., Kerminen, V.-M., Kondo, Y., Liao, H., Lohmann, U., Rasch, P., Satheesh, S., Sherwood, S., Stevens, B., and Zhang, X.: Clouds and Aerosols, book section 7, Cambridge University Press, Cambridge, United Kingdom and New York, NY, USA, 571-658, https://doi.org/10.1017/CBO9781107415324.016, 2013.

Calbo, J., Gonzalez, J.-A., Badosa, J., McKenzie, R., and Liley, B.: How large and how long are UV and total radiation enhancements?, AIP Conference Proceedings, 1810, 110002, https://doi.org/10.1063/1.4975564, 2017.

Chen, T., Rossow, W. B., and Zhang, Y. C.: Radiative effects of cloud-type variations, J. Cli- mate, 13, 264-286, https://doi.org/10.1175/1520 0442(2000)013<0264:REOCTV>2.0.CO;2, 2000.

CIMO: Guide to meteorological instruments and methods of observation, World Meteorological Organization Bulletin, 8, 2014.

di Sarra, A., Di Biagio, C., Meloni, D., Monteleone, F., Pace, G., Pugnaghi, S., and Sferlazzo, D.: Shortwave and longwave radiative effects of the intense saharan dust event of 25-26 march 2010 at lampedusa (mediterranean sea), J. Geophys. Res., 116, D23209, https://doi.org/10.1029/2011JD016238, 2011.

Futyan, J. M., Russell, J. E., and Harries, J. E.: Determining cloud forcing by cloud type from geostationary satellite data, Geophys. Res. Lett., 32, L08807, https://doi.org/10.1029/2004GL022275, 2005.

Hagemann, S., Bengtsson, L., and Gendt, G.: On the determination of atmospheric water vapour from GPS measurements, J. Geophys. Res., 108, 4678, https://doi.org/10.1029/2002JD003235, 2003.

Heinle, A., Macke, A., and Srivastav, A.: Automatic cloud classification of whole sky images, Atmos. Meas. Tech., 3, 557-567, https://doi.org/10.5194/amt-3-557-2010, 2010.

Jensen, M. P., Vogelmann, A. M., Collins, W. D., Zhang, G. J., and Luke, E. P.: Investigation of regional and seasonal variations in marine boundary layer cloud properties from modis observations, J. Climate, 21, 4955-4973, https://doi.org/10.1175/2008JCLI1974.1, 2008.

Kasten, F. and Young, A. T.: Revised optical air mass tables and approximation formula, Appl. Opt., 28, 4735-4738, https://doi.org/10.1364/AO.28.004735, 1989.

Kazantzidis, A., Tzoumanikas, P., Bais, A. F., Fotopoulos, S., and Economou, G.: Cloud detection and classification with the use of whole-sky ground-based images, Atmos. Res., 113, 80-88, https://doi.org/10.1016/j.atmosres.2012.05.005, 2012.

Long, C. N., Sabburg, J. M., Calbo, J., and Pages, D.: Retrieving cloud characteristics from ground-based daytime colour all-sky images, J. Atmos. Ocean. Tech., 23, 633-652, https://doi.org/10.1175/JTECH1875.1, 2006.

Mayer, B. and Kylling, A.: Technical note: The libRadtran software package for radiative transfer calculations - description and examples of use, Atmos. Chem. Phys., 5, 1855-1877, https://doi.org/10.5194/acp-5-1855-2005, 2005.

Morland, J., Deuber, B., Feist, D. G., Martin, L., Nyeki, S., Kämpfer, N., Mätzler, C., Jeannet, P., and Vuilleumier, L.: The STARTWAVE atmospheric water database, Atmos. Chem. Phys., 6, 2039-2056, https://doi.org/10.5194/acp-6-2039-2006, 2006.

Norris, J. R., Allen, R. J., Evan, A. T., Zelinka, M. D., O'Dell, C. W. O., and Klein, S. A.: Evidence for climate change in the satellite cloud record, Nature, 536, 72-75, https://doi.org/10.1038/nature18273, 2016.

Ohring, G., Wielicki, B., Spencer, R., Emery, B., and Datla, R.: Satellite instrument calibration for measuring global climate change: Report of a workshop, B. Am. Meteor. Soc., 86, 13031313, https://doi.org/10.1175/BAMS-86-9-1303, 2005.

Pfister, G., McKenzie, R. L., Liley, J. B., Thomas, A., Forgan, B. W., and Long, C. N.: Cloud coverage based on allsky imaging and its impact on surface solar irradiance, J. Appl. Meteorol., 42, 1421-1434, https://doi.org/10.1175/15200450(2003)042<1421:CCBOAI>2.0.CO;2, 2003. 
Ramanathan, V., Crutzen, P., Kiehl, J., and Rosenfeld, D.: Aerosols, climate, and the hydrological cycle, Science, 294, 2119-2124, https://doi.org/10.1126/science.1064034, 2001.

Robinson, N.: Solar radiation, Elsevier Pub. Co, 1966.

Roesch, A., Wild, M., Ohmura, A., Dutton, E. G., Long, C. N., and Zhang, T.: Corrigendum to "Assessment of BSRN radiation records for the computation of monthly means" published in Atmos. Meas. Tech., 4, 339-354, 2011, Atmos. Meas. Tech., 4, 973-973, https://doi.org/10.5194/amt-4-973-2011, 2011.

Schade, N. H., Macke, A., Sandmann, H., and Stick, C.: Enhanced solar global irradiance during cloudy sky conditions, Meteorol. Z., 16, 295-303, https://doi.org/10.1127/0941-2948/2007/0206, 2007.

Sherwood, S. C., Bony, S., Boucher, O., Bretherton, C., Forster, P. M., Gregory, J. M., and Stevens, B.: Adjustments in the forcingfeedback framework for understanding climate change, B. Am. Meteorol. Soc., 96, 217-228, https://doi.org/10.1175/BAMS-D13-00167.1, 2015.

Sohn, B.-J.: Cloud-induced infrared radiative heating and its implications for large-scale tropical circulations, J. Atmos. Sci., 56, 2657-2672, https://doi.org/10.1175/15200469(1999)056<2657:CIIRHA>2.0.CO;2, 1999.

Sohn, B.-J. and Bennartz, R.: Contribution of water vapour to observational estimates of longwave cloud radiative forcing, J. Geophys. Res., 113, D20107, https://doi.org/10.1029/2008JD010053, 2008.

Su, W., Bodas-Salcedo, A., Xu, K.-M., and Charlock, T. P.: Comparison of the tropical radiative flux and cloud radiative effect profiles in a climate model with clouds and the earth's radiant energy system (CERES) data, J. Geophys. Res., 115, D01105, https://doi.org/10.1029/2009JD012490, 2010.

Thuillier, G., Perrin, J.-M., Keckhut, P., and Huppert, F.: Local enhanced solar irradiance on the ground generated by cirrus: measurements and interpretation, J. Appl. Remote Sens., 7, 073543, https://doi.org/10.1117/1.JRS.7.073543, 2013.
Trenberth, K.: Changes in precipitation with climate change, Clim. Res., 47, 123-138, https://doi.org/10.3354/cr00953, 2011.

Viudez-Mora, A., Costa-Suros, M., Calbo, J., and Gonzalez, J. A.: Modeling atmospheric longwave radiation at the surface during overcast skies: The role of cloud base height, J. Geophys. Res., 120, 199-214, https://doi.org/10.1002/2014JD022310, 2015.

Wacker, S., Gröbner, J., Nowak, D., Vuilleumier, L., and Kämpfer, N.: Cloud effect of persistent stratus nebulosus at the payerne BSRN site, Atmos. Res., 102, 1-9, https://doi.org/10.1016/j.atmosres.2011.06.007, 2011.

Wacker, S., Gröbner, J., and Vuilleumier, L.: A method to calculate cloud-free long-wave irradiance at the surface based on radiative transfer modelling and temperature lapse rate estimates, Theor. Appl. Climatol., 115, 551-561, https://doi.org/10.1007/s00704013-0901-5, 2014.

Wacker, S., Gröbner, J., Zysset, C., Diener, L., Tzoumanikas, P., Kazantzidis, A., Vuilleumier, L., Stoeckli, R., Nyeki, S., and Kämpfer, N.: Cloud observations in switzerland using hemispherical sky cameras, J. Geophys. Res., 120, 695-707, https://doi.org/10.1002/2014JD022643, 2015.

Wehrli, C.: Calibrations of filter radiometers for determination of atmospheric optical depths, Metrologia, 37, 419-422, 2000.

Werkmeister, A., Lockhoff, M., Schrempf, M., Tohsing, K., Liley, B., and Seckmeyer, G.: Comparing satellite- to ground-based automated and manual cloud coverage observations - a case study, Atmos. Meas. Tech., 8, 2001-2015, https://doi.org/10.5194/amt8-2001-2015, 2015

Wiegner, M. and Geiß, A.: Aerosol profiling with the Jenoptik ceilometer CHM15kx, Atmos. Meas. Tech., 5, 1953-1964, https://doi.org/10.5194/amt-5-1953-2012, 2012.

Zelinka, M. D., Andrews, T., Forster, P. M., and Taylor, K. E.: Quantifying components of aerosol-cloud-radiation interactions in climate models, J. Geophys. Res., 119, 7599-7615, https://doi.org/10.1002/2014JD021710, 2014. 